\title{
Dapsone-resistant leprosy
}

\author{
J M H PEARSON \\ Dhoolpet Leprosy Research Centre, Hyderabad 500 006, India
}

\begin{abstract}
Summary It is likely that in 1983 over $10 \%$ of patients with lepromatous leprosy have developed dapsone resistance; the primary resistance rate of new cases is probably about $25 \%$. Patients with active dapsone-resistant leprosy who are still receiving only dapsone monotherapy may well form a larger source of infection than all other infectious cases. Supervisable and cost-effective drug regimens designed to prevent the emergence of dapsone resistance and to control the infectivity of dapsone-resistant cases deserve urgent consideration.
\end{abstract}

Dapsone is a very good drug. In orthodox dosage (1-2 mg per kg per day, that is, $50-100 \mathrm{mg}$ daily for adults) it is unusual to get any side effects; and when used in low dosage (as occurs with acedapsone (DADDS), which releases 2-3 mg of dapsone daily) it is still active against leprosy caused by strains of Mycobacterium leprae that are fully sensitive to dapsone. ${ }^{1}$ Moreover, it has a half-life of about a day $^{2}$ which ensures that blood levels can remain in the therapeutic range even if patients' compliance with prescribed treatment is $50 \%$ or even less.

The very high therapeutic ratio (blood dapsone concentration/minimal inhibitory concentration) together with the long multiplication time (about 2 weeks) of $M$. leprae were responsible for the 10- or 12-year period that elapsed before cases of dapsone-resistant leprosy began to be seen. The earliest probable cases were observed in Sungei Buloh Leprosarium, Malaysia in about 1960 (unpublished data); these patients were among the first in the world to receive dapsone, which began to be used in Sungei Buloh in 1948. However, at that time it was only possible to suspect the diagnosis, as $M$. leprae had not yet been cultivated in the experimental animal.

One of the fortunate coincidences in leprosy was that, just when patients with dapsone-resistant leprosy began to appear, the mouse foot-pad technique for obtaining limited multiplication of $M$. leprae was discovered by Shepard. ${ }^{3}$ Thus, exactly when it was needed, it became possible to test strains of M. leprae for dapsone resistance. For this purpose the mouse foot pad may be regarded as a free-range test-tube; if $M$. leprae multiply even when the mouse is fed dapsone incorporated into the diet, the bacilli must be resistant to dapsone. 
Rees was the first to use mouse foot-pad tests to study dapsone-resistant leprosy; and, with his clinical colleagues, was the dominant worker in the field for several years. The first cases of dapsone-resistant leprosy with mouse foot-pad proof were published in $1964,{ }^{4}$ and in 1968 the first case of 'partial' resistance was recorded $^{5}$ thus initiating study of the important question of different degrees of resistance. By 1975 a series of 100 cases had been reported from Sungei Buloh. ${ }^{6}$

By this time the fact that patients could develop dapsone-resistant leprosy was well recognized, but there was much doubt about how commonly it happened. The figures from Malaysia were from a selected population of patients, most (but not all) of whom were permanent hospital inmates. It was hard to determine the denominator of the figure (i.e. the number of patients at risk from whom these cases were derived); but on an estimate of 2,000, which is probably on the low side, the prevalence in 1975 was still only about $5 \%$. More information was needed from other parts of the world, and preferably obtained by some sort of formal survey/review procedure.

At about this time the results of two such surveys became available, in Costa Rica $^{7}$ and Israel. ${ }^{8}$ These gave prevalences of 6.8 and 3.7 respectively, that is, in the same order as that seen in Malaysia. These results, however, were rather quickly overshadowed by figures from Ethiopia. In 1973 Dr Rees and his co-workers initiated the Medical Research Council (MRC) Leprosy Project in the Addis Ababa Leprosy Hospital. This hospital, with its out-patient clinics, had an effective monopoly of anti-leprosy treatment in the Addis Ababa area; and all cases with clinical suspicion of dapsone-resistant leprosy were referred to the MRC Project for assessment. Thus, though not the result of formal surveys, it was possible to obtain a fairly accurate indication both of the prevalence and of the year by year incidence of dapsone-resistant leprosy in the Addis Ababa area.

The first results of these studies appeared in $1976^{9}$ and showed a prevalence of about $10-20 \%$ (depending on whether cases with very strong suspicion, but not at that time clinically or mouse foot-pad proven, were or were not included). More alarming, however, was the incidence figure of some 50 new cases per year derived from an 'at risk' population of about 1,500 patients - that is, an incidence of $3 \%$ per year. This figure showed no change during the 5-year life-span of the MRC Project. If continued unchecked, it would ensure that about half the patients with lepromatous leprosy in the Addis Ababa area would develop dapsone resistance by the mid-1980's.

Since 1975 a number of surveys have been carried out in different parts of the world, many of them supported by THELEP and using a standard protocol developed for the purpose. These studies ${ }^{10-15}$ indicate a rather uniform pattern of $5-10 \%$ prevalence of dapsone-resistant leprosy. These figures, while reassuring in comparison with the Ethiopian results, should not lead to complacency. First of all, new cases will continue to occur (unless preventive measures are undertaken); and an annual incidence of only $1 \%$ per year will raise the prevalence to almost 
$20 \%$ in a decade or so. Secondly, without early diagnosis and effective treatment these patients will initiate an epidemic of primary dapsone-resistant leprosy.

The first results of a series of patients tested for primary dapsone-resistant leprosy were reported by Rees and his group from the MRC Project in Addis Ababa in $1977 ; ;^{16}$ they showed that 5 out of 8 patients tested were resistant to dapsone, though the resistance was in most cases low grade. Results of the full series ${ }^{17}$ confirmed the initial findings; 5 out of 14 patients living in the Addis Ababa area were resistant, as were 11 out of 15 who lived away from the city.

These results were unexpected but in retrospect logical. By the early 1970's about 50 new cases of leprosy, previously untreated, were registered for treatment each year in the Addis Ababa area; and there were about the same number of patients per year who relapsed due to the emergence of dapsone-resistant leprosy. Thus there were about equal numbers of probably sensitive and probably resistant infectious cases; the finding that, a few years later, about half the new cases had been infected with dapsone-resistant $M$. leprae was by no means unreasonable.

The primary dapsone-resistant rate is a measure of the epidemiological importance of the cases of acquired (secondary) resistance. A number of surveys to determine the primary resistance rate have been initiated, but few results are currently available; ${ }^{18-20}$ rates from 4 to $60 \%$ have been observed. The largest series has been obtained as part of the THELEP multidrug trials in India and West Af rica. ${ }^{21}$ Tests for primary dapsone resistance were initiated in all these patients before treatment was commenced; both centres show rates of about $30 \%$.

One may optimistically summarize the probable general situation in regard to dapsone-resistant leprosy as follows:

1 In most parts of the world about $10 \%$ of patients with lepromatous leprosy have already relapsed with dapsone-resistant leprosy. A further $1 \%$ or more will continue to relapse each year. If they are not treated with non-sulphone drugs they will be transmitting dapsone-resistant leprosy to their contacts.

2 In most parts of the world a significant proportion of new cases are already infected with dapsone-resistant strains of $M$. leprae. These patients will, however, improve for a while on dapsone monotherapy in full dosage unless the bacilli show very high grade resistance.

Three large-scale objectives for leprosy chemotherapy can now be defined. The first, and the one to which most attention has been directed, is to apply 'maximal' treatment regimens which offer the prospect of cure to most patients, even those with lepromatous leprosy, and even if they are infected with dapsone-resistant strains of $M$. leprae. Such a regimen is currently advocated by WHO. ${ }^{22}$ It is demanding both financially and operationally, particularly as regards supervision (often a weak link in leprosy control programmes). Even if government and voluntary agencies give the greatest priority to the supply of 
drugs and training of personnel, it will be extremely difficult to apply this regimen universally in the next decade.

The second and third objectives are aimed towards controlling the spread of leprosy. The second, and easier to attain, is to apply supplementary chemotherapy to prevent the emergence of dapsone resistance in patients apparently responding well to dapsone monotherapy. Patients with secondary dapsoneresistant leprosy now make up a significant proportion of all infectious cases, and simple ways of cutting short the present epidemic of dapsone-resistant leprosy deserve urgent investigation.

The third objective is to apply cost effective and supervisable drug regimens which are as effective against dapsone-resistant leprosy as dapsone (taken regularly and in full dosage) is against fully sensitive strains of $M$. leprae. The spread of primary dapsone-resistant leprosy can only be controlled by the early diagnosis and effective treatment of patients with secondary dapsone resistance. Diagnosis can readily be achieved under field conditions by straightforward surveys; but more needs to be known about cost-effective treatment to control the disease, render patients non-infectious, maintain non-infectivity for many years, and avoid multiple drug resistance.

\section{Acknowledgements}

I am grateful to many colleagues who have helped me to see the problem of dapsone-resistant leprosy in the context of leprosy control, and particularly Dr U Kyaw Lwin, Dr U Maung Maung Gyi, and Dr J C Cap. Dhoolpet Leprosy Research Centre is the 'City Centre Clinic' of Victoria Hospital, Dichpalli.

\section{References}

${ }^{1}$ McRae DH, Russell DA, Scott CG, Vincin DR, Shepard CC. Four-year results in the therapeutic trial of acedapsone (DADDS) in the Karimui, New Guinea. Internat J Lepr, 1972; 40: $222-3$.

2 Colston MJ, Ellard GA, Gammon PT. Drugs for combined therapy: experimental studies on the anti-leprosy activity of ethionamide and prothionamide, and a general review. Le pr Rev, 1978; 49: $115-26$.

${ }^{3}$ Shepard CC. The experimental disease that follows the injection of human leprosy bacilli into foot pads of mice. J exp Med, 1960; 112: 445-54.

${ }^{4}$ Pettit JHS, Rees RJW. Sulphone resistance in leprosy. An experimental and clinical study. Lancet, 1964; 2: 673-4.

${ }^{5}$ Pearson JMH, Pettit JHS, Rees RJW. Studies on sulphone resistance in leprosy. 3. A case of 'partial' resistance. Internat J Lepr, 1968; 36: 171-8.

${ }^{6}$ Pearson JMH, Rees RJW, Waters MFR. Sulphone resistance in leprosy: a review of one hundred proven clinical cases. Lancet, 1975; 2: 69-72.

7 Peters JH, Shepard CC, Gordon GR, Rojas AV, Elizondo DS. The incidence of DDS resistance 
in lepromatous patients in Costa Rica: their metabolic disposition of DDS. Internat J Lepr, 1976; 44: 143-51.

${ }^{8}$ Levy L, Rubin GS, Sheskin J. The prevalence of dapsone-resistant leprosy in Israel. Lepr Rev, 1977; 48: 107-12.

9 Pearson JMH, Ross WF, Rees RJW. DDS resistance in Ethiopia: a progress report. Internat $J$ Lepr, 1976; 44: 140-2.

${ }^{10}$ Balraj V, Jesudasan K, Chacko CJG, Christian MC, Taylor PM, Fritschi EP, Job CK. Prevalence of secondary dapsone resistance in Gudiyatham Taluk, the leprosy control area of the Schieffelin Leprosy Research and Training Centre, Karigiri. 1. Preliminary report. Internat J Lepr, 1980; 48: 397-401.

11 Almeida JG, Christian MC, Chacko CJG, Taylor PM, Fritschi EP. Prevalence of secondary dapsone resistance in Gudiyatham Taluk, the leprosy control area of the Schieffelin Leprosy Research and Training Centre, Karigiri, 2. A progress report. Le pr. Rev, 1982; 53: September.

12 Ji Baohong, Chen Jiakun, Zhang Jialin, Hou Yuhong, Ni Guoxing, Zhang Renbao. Secondary dapsone-resistant leprosy in Shanghai Municipality. Lepr Rev, 1983; 54: September.

13 Pattyn SR, Van Loo G, \& Sansarricq H. Quatre cas de lepre dapsone resistants en Haute-Volta. Med. Afrique Noire, 1981; 28: 147-8.

14 Final Report of the Regional Working Group on Drug Policy and Operational Research in the Leprosy Programme. Unpublished document ICP/BVM/005 issued by the WHO Regional Office for the Western Pacific, Manila, 1981.

15 Baquillon G, Ferracci C, Saint Andre P, Pattyn SR. Dapsone-resistant leprosy in a population of Bamako (Mali). Lepr Rev, 1980; 51: 315-19.

16 Pearson JMH, Haile GS, Rees RJW. Primary dapsone-resistant leprosy. Lepr Rev, 1977; 48: 129-32.

17 Pearson JMH, Haile GS, Barnetson RStC, Rees RJW. Dapsone-resistant leprosy in Ethiopia. Lepr Rev, 1979; 50: 183-99.

18 Guinto RS, Cellona RV, Fajardo TT, de la Cruz EC. Primary dapsone-resistant leprosy in Cebu, Philippines. Internat J Lepr, 1981; 49: 427-30.

19 Utji R, Kohasih A, Santoso AUS. Dapsone-resistant leprosy in Jakarta: a preliminary report. Lepr Rev, 1983; 54: September.

${ }^{20}$ Girdhar BK, Sreevasta, Desikan KV. Primary sulphone resistance. A preliminary report. Lepr India, 1978; 50: 352-5.

${ }^{21}$ Sub-committee on Clinical Trials. THELEP-controlled clinical trials in lepromatous leprosy. Primary resistance to dapsone in Bamako and Chingleput. Lepr Rev, 1983; 54: September.

22 WHO Study Group. Chemotherapy of Leprosy for Control Programmes. Technical reports series 675. WHO: Geneva, 1982. 